The Geneva Papers on Risk and Insurance, 20 (No. 77, October 1995) 463-473

\title{
Impact of Catastrophes on the Reinsurance Industry
}

\author{
by John Engeström*
}

\section{Importance of natural catastrophe reinsurance}

Catastrophes catch everybody's attention. Their negative impact on reinsurance markets have similarly attracted a lot of attention recently. The grim scenarios range from the impending demise of reinsurers due to ever increasing natural catastrophe losses to dramatic reduction in reinsurance capacity, primary market "red-lining" and government takeover of natural catastrophe reinsurance. What lessons can we draw from the events of the last few years and how should we assess the future of natural catastrophe reinsurance?

Does the health or indeed the very existence of a natural catastrophe reinsurance market matter? In view of the recent unpredictability of natural catastrophe reinsurance markets would it not be preferable for primary insurers to self-insure these risks?

The combination of low frequency and high severity makes it very hard to properly fund for individual insurance company natural catastrophes exposures. It is actuarially not improbable that once-in-thirty-year natural catastrophe losses occur twice within five years. It is equally not illogical that some individual companies may escape relatively unscathed twice over. Very large and infrequent losses cannot effectively be self-funded by individual companies, not even by any one country or market in the case of cataclysmic events. Natural catastrophe exposures are a typical example of risks that need to be spread over time, over geographic regions and between a multitude of players. In conclusion, natural catastrophe reinsurance availability therefore matters very much to the primary insurance market.

But does it really matter to reinsurers whether they participate in this market? Would their incomes really suffer if they were to abstain? To answer this question, let's first consider the overall size of the natural catastrophe reinsurance market.

Let me preface most of the numbers that will follow with a health warning. It is notoriously difficult to obtain reliable data in most areas related to natural catastrophe reinsurance. Therefore, many conclusions will be based on assumptions, and often M\&G's own internal assumptions.

\footnotetext{
* Chief Executive, Mercantile \& General Reinsurance Group.
} 
We estimate that worldwide natural catastrophe reinsurance XL premiums in 1995 will amount to approximately $\$ 6 \mathrm{bn}$. Relating this number to the estimated worlwide net non-life reinsurance premiums of around $\$ 150 \mathrm{bn}$ we arrive at a relative share of around $4 \%$. We then have to add the portion of natural catastrophe reinsurance premiums contained within proportional covers. Let's assume this represents $5 \%$ of total fire reinsurance premiums $(22 \%$ of non-life total) or $1 \%$ of total non-life premiums. Total global natural catastrophe reinsurance premiums would then be around $5 \%$ of non-life premiums.

By all accounts this is not a large share. Theoretically, reinsurers could collectively abstain from this income without severe implications. However, our clients the primary insurers rely on reinsurers to perform this global risk spreading function. If traditional reinsurers would not supply this product then our clients would have to reinvent a substitute. This is obviously in nobody's interest. We should therefore strive to arrive at efficient and equitable solutions underpinned by mutual trust and open sharing of information.

We can thus conclude that natural catastrophe reinsurance represents a small but vital portion of the total reinsurance market, indeed of the world economy.

\section{Who are the major buyers and sellers of natural catastrophe reinsurance}

Based on distribution of worldwide reinsurance premiums in 1992 (as published by Swiss Re/Sigma) one can attempt to quantify the major buying markets in the world. The driver is the respective hypothesis regarding percentage of natural catastrophe reinsurance XL premiums per market.

Table 1

\begin{tabular}{|c|c|c|c|}
\hline & $\begin{array}{l}\text { Proportion } \\
\text { Cat Re XL }\end{array}$ & $\begin{array}{c}\text { Ceded Cat Re } \\
\text { XL Premium } \\
\$ B N\end{array}$ & $\begin{array}{c}\text { Share of Ceded } \\
\text { Cat Premium }\end{array}$ \\
\hline Europe & $4 \%$ & 2.7 & $45 \%$ \\
\hline US & $3 \%$ & 1.4 & $23 \%$ \\
\hline Japan & $5 \%$ & 0.6 & $10 \%$ \\
\hline $\begin{array}{l}\text { Rest of Asia/At } \\
\text { Latin America } \\
\text { Rest of World }\end{array}$ & $5 \%$ & 1.3 & $22 \%$ \\
\hline Total & $4 \%$ & 6.0 & $100 \%$ \\
\hline
\end{tabular}

Under M\&G's assumptions Europe is by far the biggest buyer, twice the size of the US. This may seem strange given the many recent catastrophes in the US but is explained by uninsured deductibles and high retentions.

Even though Japan looks like a high proportion for a single country it masks a bigger need. Both the US and Japan could and should really buy more cover but do not due to differing views between buyers and sellers on price, and to a lesser degree lack of capacity. 
Regarding sellers of natural catastrophe reinsurance we get into even more conjecture due to lack of data. A plausible distribution of the estimated $\$ 6 \mathrm{bn}$ of natural catastrophe reinsurance XL premium might be:

Table 2

\begin{tabular}{|lccc|}
\hline & $\begin{array}{c}\text { Assumed } \\
\text { Cat Re XL Prem } \\
\text { \$bn }\end{array}$ & $\begin{array}{c}\text { Share of Assumed } \\
\text { Cat Re XL Prem }\end{array}$ & $\begin{array}{c}\text { Assumed Less } \\
\text { Ceded Cat Prem } \\
\text { \$bn }\end{array}$ \\
\hline Europe (incl. London) & 3.1 & $52 \%$ & +0.4 \\
Bermuda & 1.3 & $22 \%$ & +1.3 \\
US & 1.1 & $18 \%$ & -0.3 \\
Rest of World (incl. Japan) & 0.5 & $-10 \%$ & -1.4 \\
Total & 6.0 & & \\
\hline
\end{tabular}

Looking at the two tables we can conclude that the rest of the world and especially Japan, together with the US are net importers of natural catastrophe capacity. Bermuda obviously is the undisputed export leader with Europe being a respectable exporter of capacity. To complete the picture one would have to recognise the considerable US capital contributions to the Bermuda market.

\section{Estimated natural catastrophe reinsurance capacities $\mathbf{1 9 9 5}$}

Starting with our estimated distribution of ceded catastrophe XL premiums we can make certain assumptions regarding average rate-on-line and thus total capacity made available per area.

Table 3

\begin{tabular}{|lccc|}
\hline Area & $\begin{array}{c}\text { Nat Cat Re XL Premium } \\
\text { \$bn }\end{array}$ & $\begin{array}{c}\text { Average } \\
\text { ROL }\end{array}$ & $\begin{array}{c}\text { Cover Bought } \\
\text { \$bn }\end{array}$ \\
\hline Europe & 2.7 & $9 \%$ & 30 \\
US & 1.4 & $15 \%$ & 9 \\
Japan & 0.6 & $10 \%$ & 6 \\
Rest of World & 1.3 & $5 \%$ & 26 \\
\cline { 2 - 3 } Total & 6.0 & $8.5 \%$ & 71 \\
\hline
\end{tabular}

It is important to point out that the amount of cover bought represents the sum total of all regional covers within the larger (continental) areas. Therefore, we should not draw the erroneous conclusion that - for example - Europe is "covered" for a $\$ 30 \mathrm{bn}$ event. Even more relevant, the US is not covered for a regional reinsurance loss of $\$ 9 \mathrm{bn}$. These numbers again serve to highlight the parsimonious amount of reinsurance cover bought by the US and Japanese markets. 
Latin America and Australia/New Zealand are the largest buyers of natural catastrophe reinsurance in the rest of the world.

The relatively high average rate-on-line for US catastrophe covers obviously reflects the very poor recent experience combined with a greater appreciation of the enormous exposures.

Let's now try to quantify our perception of per programme capacity as of the most recent renewals. Again, this is not an exact science but a reasonable approximation.

Table 4

\begin{tabular}{|c|c|c|c|c|c|c|}
\hline \multirow{2}{*}{ Area } & \multicolumn{6}{|c|}{ Programme Capacity/Placement } \\
\hline & Total & US & Bermuda & London & $\begin{array}{l}\text { Continental } \\
\text { Europe }\end{array}$ & $\begin{array}{l}\text { Rest of } \\
\text { World }\end{array}$ \\
\hline \multicolumn{7}{|l|}{ 1. $\$ m$} \\
\hline US WS \& EQ & 270 & 90 & 95 & 60 & 20 & 5 \\
\hline Europe WS \& EQ & 350 & 5 & 50 & 140 & 140 & 15 \\
\hline \multicolumn{7}{|c|}{$L_{1}$} \\
\hline Japan WS & 630 & \multicolumn{2}{|c|}{210} & 210 & 210 & - \\
\hline Japan EQ (pro rata) & 650 & \multicolumn{2}{|c|}{165} & 325 & 160 & - \\
\hline \multicolumn{7}{|l|}{ 2. Percent } \\
\hline US WS \& EQ & & $33 \%$ & $35 \%$ & $22 \%$ & $8 \%$ & $2 \%$ \\
\hline \multirow[t]{2}{*}{ Europe WS \& EQ } & & $2 \%$ & $14 \%$ & $40 \%$ & $40 \%$ & $4 \%$ \\
\hline & & & † & & & \\
\hline Japan WS & \multicolumn{3}{|c|}{$33 \%$} & $33 \%$ & $34 \%$ & - \\
\hline Japan EQ (pro rata) & \multicolumn{3}{|c|}{$25 \%$} & $50 \%$ & $25 \%$ & - \\
\hline
\end{tabular}

As we all know per programme capacities came down dramatically in 1992/93 to be partially re-inflated in 1994 through the new Bermuda capacity.

The relatively high Japanese per programme capacity is a reflection of a very concentrated market with a few large buyers and especially one specific programme. These capacities still remain well below those available in the late eighties/early nineties. They are also short of the real need of these markets.

\section{Economic and insured natural catastrophe losses}

There is a clear trend towards an increased proportion of insured catastrophe losses. Whereas the insured share was relatively stable during the sixties and seventies at slightly more than $10 \%$, this share has grown to a third over the last 10 years. This trend still seems to be accelerating as evidenced by the 6 largest economic losses through the end of 1994 and their insured portion. It is also notable that the 6 largest economic losses occurred in each of the last 6 years. 
Table 5

\begin{tabular}{|lcccc|}
\hline & & \multicolumn{2}{c}{ Nat Cat Losses \$bn } & Insured \\
\cline { 3 - 4 } Event/Year & Area & Economic & Insured & Portion \\
\hline Andrew/92 & US & 30 & 18 & $60 \%$ \\
LA EQ/94 & US & 30 & 11 & $37 \%$ \\
Winter Storms/90 & Europe & 15 & 10 & $67 \%$ \\
Floods/93 & US & 12 & 1 & $8 \%$ \\
Hugo/89 & US/Carib. & 9 & 4.5 & $50 \%$ \\
Mireille/91 & Japan & 6 & 5 & $83 \%$ \\
\hline
\end{tabular}

What conclusion can we draw regarding the probable insured portion of future natural catastrophe losses? Also taking into account other recent natural catastrophe losses we have the following working assumptions within the $M \& G$.

Table 6

\begin{tabular}{|llc|}
\hline Event & Area & Insured Loss Portion (Range) \\
\hline \multirow{2}{*}{ Storm } & US & $50-70 \%$ \\
& Europe & $60-70 \%$ \\
& Japan & $67-83 \%$ \\
Earthquake & US & $17-33 \%$ \\
& Europe & $50-67 \%$ \\
& Japan & $10-30 \%$ \\
& US & $5-15 \%$ \\
& Europe & $5-15 \%$ \\
\hline
\end{tabular}

\section{Sharing of natural catastrophe losses}

There are essentially four interested parties: insureds, insurers, reinsurers and various local and national government entities. All four carry their portion of risk currently.

- Insureds through deductibles or co-insurance as well as under-insurance. We also include un-insurance in this category.

- Insurers carry underlying retentions, co-reinsurance and un-reinsured exposure to cataclysmic events.

- Reinsurers can individually protect themselves through retrocession, but collectively retain all their risks (apart from cessions to possible government pools). 
- Governments are exposed through un-insured or self-insured government property, through state-run primary schemes (quite common for flood risk) and through staterun reinsurance pools. However, arguably their greatest real exposure is through their political and moral obligation to help victims who are un-insured or inadequately insured.

The sharing of catastrophe risk had been unduly lopsided until very recently with reinsurers carrying a very large share of the exposure for quite an inadequate amount of premium. The reinsurance industry has only got itself to blame for this state of affairs. Firstly, the market tended to effectively experience rate catastrophe covers. Secondly, we lacked (and often did not even ask for) sufficient exposure information. Thirdly, we failed to properly recognise the trend in severity increases.

The effect of all these factors was that reinsurers were for ever playing catch up, effectively trying to post-fund rather than pre-fund losses. Worse even, by not recognising the true exposures we failed to see the need to cap the cover granted under proportional treaties. We were taking on unlimited exposures against a limited capital base. Putting it differently, we were gambling with our shareholders money against very poor odds.

This state of affairs had to end in tears. Reinsurers paid out enormous amounts during 1989 through 1992. A violent, but necessary price correction took place. Ceding company retentions were increased, reinsurance capacity reduced (partly through reinsurers' losses reducing surplus) and exposures were gradually getting capped under pro rata treaties. This latter action has not been adequately implemented in all markets yet, but responsible reinsurers will insist that it happens.

We must now make sure that there is a fair sharing of risk between the four parties.

- It is in the interest of the insured to carry reasonable deductibles or co-insurance. These events are very infrequent for individual insureds, so it is economically efficient to carry higher deductibles than for motor or homeowners' covers. Higher deductibles will also reduce the claims handling cost for insurers and, especially co-insurance will act as a restraining element on fraudulent or inflated claims.

- Insurers should determine how much retention they wish to carry in relation to their capital and surplus. The retention should be in three sections. The underlying retention will take care of that portion of higher frequency and low severity events which is inefficient to reinsure. A level of co-reinsurance in the catastrophe programme is by now almost a standard requirement from reinsurers. At the very top of the exposure there should be another area of retention for the one-in-a-hundred or one-in-a-thousand year cataclysmic event. Shareholders capital and surplus is meant to act as a cushion for such events. A typical distribution of a $10 \%$ surplus exposure would be $3 \%$ as underlying retention, 1-2\% co-reinsurance and 5-6\% exposed at the very top.

- Reinsurers tend to keep an increasing share of their catastrophe exposures for net account. Concerns about financial security aspects and artificial loss spirals have shrunk the retro market. Like in the case of primary insurers the distribution of net retention would be pegged at a percentage of net assets, similarly distributed between underlying retention, co-reinsurance and exposure above the retro programme. It is absolutely essential that reinsurers have a quantifiable exposure to natural catastrophe losses. This is achieved through a combination of capped proportional treaties and improved exposure information. 
- Governments - in their widest definition - already act as insurer, reinsurer and social safety net in the event of natural catastrophes. Some parts of our industry fear that government's involvement as a reinsurer will threaten the "free market". We should not worry about that. No modern government is awash with money to the extent that they would want to unduly extend their already excessive social commitments. They can, however, provide a more efficient financing mechanism for politically motivated or infrequent cataclysmic losses. They can raise funds - should the need arise - through taxation and cheap borrowing. Having governments involved in high level natural catastrophe protection also engages them in technical discussions with the insurance industry. This will make them understand our problems and challenges and make them more sympathetic to our requirements. This is clearly evidenced in the US where the Natural Disaster Coalition has helped to raise awareness of these issues.

Can we attempt to quantify what the relative burden of each of the four interested parties is? Consistent with our assumptions of the relationship between insured and economic loss we use the following distribution within the M\&G.

Table 7

\begin{tabular}{|c|c|c|c|c|c|c|c|}
\hline \multirow[t]{3}{*}{ Event } & \multirow[t]{3}{*}{ Area } & \multicolumn{2}{|c|}{ Economic Loss } & \multicolumn{3}{|c|}{ Insured Loss } & \multirow{3}{*}{$\begin{array}{l}\text { Split } \\
\text { Insurer/ } \\
\text { Reinsurer }\end{array}$} \\
\hline & & Insured & Govts & Total & Insurance & Reinsurance & \\
\hline & & \multicolumn{5}{|c|}{ (Percent of total economic loss) } & \\
\hline \multirow{3}{*}{ Storm } & US & 15 & 25 & 60 & 36 & 24 & $60 / 40$ \\
\hline & Europe & 5 & 28 & 67 & 27 & 40 & $40 / 60$ \\
\hline & Japan & 5 & 25 & 70 & 49 & 21 & $70 / 30$ \\
\hline \multirow[t]{3}{*}{ Earthquake } & US & 20 & 55 & 25 & 15 & 10 & $60 / 40$ \\
\hline & Europe & 25 & 25 & 50 & 15 & 35 & $30 / 70$ \\
\hline & Japan & 10 & 75 & 15 & 9 & 6 & $60 / 40$ \\
\hline \multirow[t]{2}{*}{ Flood } & US & 10 & 80 & 10 & 7 & 3 & $70 / 30$ \\
\hline & Europe & 30 & 60 & 10 & 3 & 7 & $30 / 70$ \\
\hline
\end{tabular}

The split between insurers and reinsurers obviously depends on the magnitude of the catastrophe loss. The above estimates are situated around the maximum losses forecast to date. Note that the Japanese earthquake loss from kobe showed a much lower involvement for insurers and reinsurers due to the low level of earthquake cover purchased. The above sharing is more representative of a Tokyo event.

\section{Trending of natural catastrophe losses}

What has caused the sharp increase in insured natural catastrophe losses since 1989? Is it due to frequency or severity or both?

Increased frequency of weather-related losses would be tied into climatic change. There is ample evidence that the "greenhouse effect" and ensuing global warming have led to 
increased disturbances in the weather patterns. What some scientists still debate is whether recent changes are a mere "blip" on the long term trends or whether they constitute a real trend break. Suffice it to say that - regardless of frequency - the irrefutable increases in the severity of insured natural catastrophe losses is proof enough that we are faced with a steep increase in the trend curve.

What are the reasons for this increase in the insured cost of catastrophe losses? We have already alluded to some of them.

1. Increased wealth and increased interdependencies. As we become more affluent we acquire more expensive homes, own more expensive cars, household equipment and decorative items. Our factories have become high tech process oriented production sites with a high value concentration and high degree of interdependency with suppliers and customers. Business interruption losses often exceed pure property losses.

2. Increased insurance propensity. People tend to insure their property more. Growth in non-life insurance and reinsurance consistently outpaces growth in GDP.

3. Concentration of wealth in exposed areas. Ease of transportation and quality of living make us concentrate along the shorelines and seek to live in warmer climes. These are often the very areas most exposed to natural catastrophes. The migration towards the Sun Belt in the US is a prime example. People elect to live on the fault lines in California and on low-lying beaches like the Keys in Florida. Gradually large conurbations with high value infrastructure are established in these exposed areas.

So, if we can safely conclude that the cost of insured natural catastrophe losses will continue to increase, at what level should we pitch our estimate for natural catastrophe losses in the near future? At the $M \& G$ we estimate the yearly cost of global insured natural catastrophe losses to come in between $\$ 5$ bn and $\$ 25$ bn with a realistic mid-point at $\$ 15$ bn.

\section{Adequacy of natural catastrophe reinsurance premiums}

Are natural catastrophe reinsurance premiums sufficient to pay for expected losses to reinsurers?

Table 8

\begin{tabular}{|lr|}
\hline & $\begin{array}{r}\text { bn } \\
\text { Expected average insured natural catastrophe losses }\end{array}$ \\
Whereof reinsured portion 30-70\%, say 50\% & 15.0 \\
Natural catastrophe reinsurance XL premiums 1995 estimate & 7.5 \\
Estimated pro rata natural catastrophe premiums (1\% of WW) & +1.5 \\
Total gross premiums & 7.5 \\
Deduct brokerage and internal costs 15\% & -1.0 \\
Net premium estimate & -6.5 \\
\hline
\end{tabular}


The conclusion would therefore seem to be that natural catastrophe reinsurance premiums would have to increase further. This is contrary to the average $10-15 \%$ reductions we experienced in the most recent renewals. Why did the market behave in this irrational fashion? Part of the answer is that in almost all markets of the world reliable exposure information is still lacking. When pricing individual treaties many actors in the market still prefer to succumb to optimistic specific assumptions rather than consider global trends. Above all, however, the market is still largely looking at experience rather than exposure. 1994 was not a good natural catastrophe year with insured losses somewhere around $\$ 16 \mathrm{bn}$. About $\$ 12 \mathrm{bn}$ came from the North Ridge earthquake alone. Using optimistic assumptions on reinsured losses this event might have cost reinsurers about $25 \%$ or $\$ 3.0 \mathrm{bn}$. If the remaining approximately $\$ 4$ bn of losses are $50 \%$ reinsured then total natural catastrophe reinsurance losses would be around $\$ 5 \mathrm{bn}$, leaving a "profit" of some $\$ 1.5 \mathrm{bn}$. Sadly, one year's tenuous results seem to be sufficient "experience" to price a product that should be exposure rated.

\section{Pricing and capacity dichotomy}

It is therefore logical to conclude that natural catastrophe reinsurance premiums will need to rise further to attract sufficient capital to meet the real exposures. The pricing/ capacity dichotomy is most acute in the US and Japan. In these markets primary companies have apparently decided that budgetary constraints on natural catastrophe reinsurance costs are more important than the long term safeguard of their capital base. Most companies, especially the major players, run enormous retentions to cataclysmic events. Japanese windstorm programmes typically cover a revalued Mireille loss, or a \$6-7bn insured event. We all know this is far from a worst case scenario. In the US Andrew cost $\$ 18$ bn to insurers and North Ridge $\$ 12$ bn with total economic loss of around $\$ 30$ bn in both instances. Realistic estimates of maximum insured losses from US windstorm are $\$ 86 \mathrm{bn}$ and for a New Madrid earthquake \$101bn (as per US Natural Disaster Coalition).

Would properly rated natural catastrophe reinsurance covers attract more capacity? On the evidence of what happened in the Bermuda market in 1993/94 this would seem likely.

One obvious way in which governments could assist in building up capacity would be to allow gradual tax free accumulation of natural catastrophe reserves. While this is already the case in most continental European countries, and indeed in Bermuda, the US and UK governments do not seem disposed to give the insurance industry any real tax break.

\section{Reinsurers' capital and surplus in relation to cataclysmic losses}

Will the world reinsurance community be able to pay its share of the "Big One" or a series of "Big Ones"?

To answer this question we must try to determine what level of true net assets exist in the world reinsurance market. Differing accounting conventions across the world make it impossible to simply add up capital and surplus numbers from published accounts. If we use a multiple of premiums as a proxy for net assets we would probably get a more realistic number. Solvency ratios or percentages vary between different areas of the world with a spread of solvency ratios from $0.6: 1$ to $3: 1$ or expressed as solvency percentages from $33 \%$ to $167 \%$. Our estimate of a weighted average is $1.35: 1$ or $75 \%$ solvency. Based on $\$ 150 \mathrm{bn}$ of premiums this would indicate a level of global net assets of around $\$ 110 \mathrm{bn}$.

How much would reinsurers pay for the "Big One"? 
Table 9

\begin{tabular}{|c|c|c|c|c|c|}
\hline \multirow[t]{2}{*}{ Loss Event } & \multirow{2}{*}{$\begin{array}{c}\text { Cataclysmic } \\
\text { Economic Loss } \\
\$ \text { bn }\end{array}$} & \multicolumn{2}{|c|}{ Insured Loss } & \multicolumn{2}{|c|}{$\begin{array}{c}\text { Theoretical } \\
\text { Reinsured Loss }\end{array}$} \\
\hline & & $\%$ Econ. & \$bn & $\%$ Insured & $\$$ bn \\
\hline US Earthquake & $400(?)$ & $25 \%$ & 100 & $10 \%$ & 40 \\
\hline US Windstorm & $140(?)$ & $60 \%$ & 85 & $24 \%$ & 34 \\
\hline Japan Earthquake & $750(?)$ & $15 \%$ & 112 & $6 \%$ & 45 \\
\hline
\end{tabular}

It should be noted that theoretical reinsurance losses of $\$ 35$ bn to $\$ 45$ bn vastly exceed the amount of natural catastrophe XL capacity that can be bought in today's market. Even if losses under proportional covers are added in we would probably not exceed a reinsured loss of $\$ 15 \mathrm{bn}$. A hit to reinsurers surplus of some $\$ 15 \mathrm{bn}$ would correspond to $14 \%$ of global reinsurance net assets.

Another imponderable is the impact on financial markets of such events. There would be a need to realise enormous amounts of assets and to issue new debt to pay for the losses. Would this lead to a "melt-down" of financial markets? If asset values were to fall $10 \%$, and if we assume a 3:1 gearing between invested assets and net assets, then financial markets could wipe out $30 \%$ of capital and surplus, in addition to the $14 \%$ already lost from the pure catastrophe loss. You may well consider a net asset loss of around $40 \%$ a doom's day scenario, but the truth is that nobody really knows what is the most likely outcome.

\section{Other catastrophic threats to the insurance and reinsurance industry}

We may well reflect with gloom on the destructive potential of natural catastrophes. Alas, far worse disasters threaten our industry if we cannot reverse the trend - most obvious in the US - where politicians and the judiciary retroactively change the contractual framework for determining liability for environmental impairment and latent diseases. Going for the "deep pockets" of the insurance and reinsurance industry is both immoral and an illusion.

An illusion, because those pockets are nowhere near deep enough. The total capital and surplus of the US Property and Casualty industry is around $\$ 180 \mathrm{bn}$. The global non-life industry surplus can be "guestimated" at around $\$ 400 \mathrm{bn}$. Total costs connected with Superfund alone have been estimated around $\$ 170 \mathrm{bn}$. Add to that number the cost of pollution outside of waste sites and the cost of latent diseases. Asbestosis alone may well end up costing in excess of $\$ 100 \mathrm{bn}$. Breast implants are the most recent example of US multibillion dollar costs to the insurance industry. Looming on the horizon are electromagnetic fields, tobacco, potentially alcohol and probably a whole host of problems not yet identified. The total potential cost of a political and judiciary system gone haywire may have to be measured in double digit trillions of dollars. $\$ 400 \mathrm{bn}$ of global insurance surplus would be wiped out several times over.

Making the insurance and reinsurance industry pay for these societal sins is also immoral. Insurance contracts never explicitly covered these risks and certainly not to the extent where a one year policy could be construed to cover 30 years plus of exposure, as under the 
asbestosis "triple trigger" theory. "Retroactive" and "joint-and-several" liability concepts introduced to raid the maximum number of "deep pockets" represent flagrant breaches of internationally accepted legal principles.

Our industry must act vigorously to help reverse the US liability trends. We must also make sure that European politicians and legislators are not tempted to rewrite the rules to emulate the American example. Making the insurance industry act as indirect tax collectors is not the solution to inadequate past regulations and lack of awareness of environmental issues in years gone by.

If the legal liability system is allowed to scupper the insurance and reinsurance industry, then natural catastrophe worries will be an irrelevance!

But let us not get depressed by an Armageddon scenario. What can we do to make the global natural catastrophe market more efficient?

\section{International solutions to global problems}

The major impediment to a well functioning and rational catastrophe market is the lack of reliable information. Developing proper exposure information is as vital to insurers as to reinsurers. For years, international reinsurers have - somewhat timidly - been asking for information in the context of CRESTA, mostly focused on earthquake. Initially, this effort was resisted by primary markets. Today the mood has changed for the better. The major impediment now is lack of sufficient systems capability to gather and analyse exposure information.

It is encouraging to see that industry associations - like the ABI in the UK for flood risk - are contributing to the effort of quantifying exposures. An even more broad based undertaking is making good headway in the US through the activities of the Natural Disaster Coalition.

The complexity of the issues involved makes the task far too daunting for any individual insurer or reinsurer. It is in everybody's interest that we share in both the cost and the fruits of finding a reliable mechanism for the global catastrophe market. Let us not forget that governments also have a role to play both as funders of research, as participants in the risk sharing and as reasonable tax collectors (hopefully this is not an oxymoron).

For our part, the $M \& G$ is engaged in a number of ventures and collaborative efforts to further the understanding of the global natural catastrophe issues. We have shared with you some of our internal assumptions used to assess these risks. The paucity of reliable data is a major problem. At the $M \& G$ we hope that this overview of the natural catastrophe market may lead to an active discussion around some of the underlying assumptions and issues. 